\title{
Prevalence and Risk Factors of Hypertension in the Urban Population of Iran
}

Mojgan Khatibi ${ }^{1 *}$, Shima Bagherzadeh², Haleh Aghamolaey ${ }^{3}$ and Hamid Najafipour ${ }^{4}$

${ }^{1}$ Endocrinology and metabolism Research Center, Institute of Basic and Clinical Physiology Sciences, Kerman University of Medical Sciences, Kerman, Iran ${ }^{2}$ Yerevan Haybusak University, Armenia

${ }^{3}$ Department of Biostatistics, Faculty of Paramedical Sciences, Shahid Beheshti University of Medical Sciences, Tehran, Iran

${ }^{4}$ Physiology Research Center, Kerman University of Medical Sciences, Kerman, Iran

\begin{abstract}
Objective: Hypertension is an important cause of cardiovascular diseases. Obesity is one of the factors that effect of cause and prevalence hypertension. The aim of this study is prevalence and risk factors in hypertension in urban in Kerman.

Methods: 5900 population, 3238 women and 2662 men aged $15-75$ years. Weight, height, BMI and blood pressure were measured. Pre-hypertension and hypertension were determined as $120-139 / 80-89 \mathrm{mmHg}$ and $>140 / 90 \mathrm{mmHg}$ for systolic/diastolic blood pressure, respectively.

Results: The prevalence of hypertension regards to the sex of the participants was $21.1 \%$ for men and $24 \%$ for women $(P=0.809)$ while it was $22.6 \%$ for the whole population. The prevalence of obesity was $63.9 \%$ for men and $79.0 \%$ for women and $30.3 \%$ for the whole population. The highest prevalence of obesity was belonged to those who were between 45-54 years. According to regression analysis the chance of having hypertension for those who had a weekly consumption of white grain was 0.3 more than those who consumed it on a monthly basis $(p<0.05)$.

Conclusions: Obesity is related directly to other cardiovascular diseases and mortality due to them. Based on the results of this study, the necessity of modifying nutritional cultures, nutritional education for these patients, weight control method and informing them of the impact of their diet on improving their illnesses are effective, while reducing the overthe-counter costs of clinical treatments for patients and the community.
\end{abstract}

Keywords: Hypertension; Cardiovascular diseases; Fiber; Brain strokes incidence

\section{Introduction}

The prevalence of hypertension disease is increasing in the developing countries. On the Mediterranean area, high blood pressure has affected $26 \%$ of the total population. The prevalence of hypertension has been reported about $21.7 \%$ in Mediterranean region [1,2]. In the Tehran lipid and glucose study, after balancing for age, the prevalence of hypertension was determined $19.4 \%$ in women and $23.3 \%$ in men [3] and its prevalence in Kerman was reported 12.1\% in 2005-2006. Hypertension disease in the long term leads to irreversible damage to the cardiovascular system, small vessels, and an increased probability of brain strokes incidence [3]. High blood pressure is considered itself as one of the risk factors of cardiovascular diseases.

Many factors such as heredity, environment, salt sensitivity, plasma renin level, insulin sensitivity rate, ions such as sodium, calcium, also age, race, gender, smoking, alcohol, serum cholesterol rate, glucose intolerance, obesity and overweight can have a significant effect on creating hypertension [4].

Obesity is one of the factors that its relationship with blood pressure has been reported in various studies [5-8]. Obesity is a condition in which body fat stores are increased to a degree that causes disorder in one's health [9]. Obesity diagnosis criteria that are generally used in the studies, are using indicators related to weight, special anthropometric measurements such as skin wrinkle thickness (subcutaneous fat thickness defined by the percentiles from 5-95), waist to hip circumference ratio, waist circumference, using special devices and methods for determining body fat and body mass index that is defined by numerical categorization for normal weight $(<25)$, overweight (25-29), and obesity ( $\geq 30)[10]$.
For many years, the relationship between hypertension and dietary food patterns has been mentioned. There are different opinions about the relationship between dietary patterns and the prevalence of hypertension due to differences in sex, age and races.

There are few studies in some diet components and hypertension. According to the importance of diet and weight control in hypertension control and according to this fact that the food pattern status in these patients has not been performed so far in Kerman, so, this study reviews food pattern in these patients for the first time in Kerman.

\section{Methods}

The first phase of the study known as KERCADRs, which is a population-based cohort study, was initiated from 2009-2011 among 5900 adult subjects aged $15-75$ years old in Kerman. Using a nonproportional to size one-stage cluster sampling household survey, the study samples were recruited. The study protocol of the study was approved by the Ethics Committee of the Kerman University of Medical Sciences (Ethic code 88/110 KA). An informed consent to

*Corresponding author: Mozhgan Khatibi, Endocrinology and Metabolism Research Center, Institute of Basic and Clinical Physiology Sciences, Kerman University of Medical Sciences, Kerman, Iran, Postal Code: 7619813159; Tel: +98 341 31215654; E-mail: m13842837@gmail.com

Received July 17, 2018; Accepted July 25, 2018; Published August 02, 2018

Citation: Khatibi M, Bagherzadeh S, Aghamolaey H, Najafipour H (2018) Prevalence and Risk Factors of Hypertension in the Urban Population of Iran. J Hypertens (Los Angel) 7: 253. doi: 10.4172/2167-1095.1000253

Copyright: $\odot 2018$ Khatibi M, et al. This is an open-access article distributed under the terms of the Creative Commons Attribution License, which permits unrestricted use, distribution, and reproduction in any medium, provided the original author and source are credited. 
participate was given by all subjects' prior participation in the study. The inclusion and the exclusion criteria was the age of the participants which include those who are between 15-75 years and exclude those who were under 15 and above 75 years old.

\section{Data gathering tool}

Each subject was seated in a quiet and comfortable position for $5 \mathrm{~min}$ and BP was measured, $5 \mathrm{~min}$ apart with a mercury sphygmomanometer (cuff size $12.5 \mathrm{~cm} \times 40 \mathrm{~cm}$ ) with auscultator method of BP measurement.

a) Interview: Every participant was interviewed by a trained questioner in order to gather data. Furthermore, a trained doctor reviewed different risk factors of coronary heart disease and measured blood pressure. Data related to the present study including demographic data (age and gender and height and weight) and education level (illiterate, primary to high school and high school and higher) were gathered. Getting food was gathered and recorded by FFQ questionnaire that its reliability and validity have been measured. This questionnaire was used to evaluate the consumption of food groups. The consumption of food groups was placed in two food patterns of meats-fats-sugars and cereals-vegetables-fruits and was evaluated. Frequency of use was categorized into weekly and monthly.

b) Blood pressure definition: Blood pressure was evaluated by a doctor and by using the mercury sphygmomanometer and after at least 5 min rest. This blood pressure was evaluated for the second time (at least after $30 \mathrm{~min}$ interval) by using right hand's arm and in sitting position. Finally, the average of evaluation for two times was considered as diastolic and systolic blood pressure. In addition to blood pressure measuring, the patients were asked about previous record of hypertension disease and the ones who received anti-hypertension drug were also considered among the patients who had hypertension. Data were analysed using STATA12. Regression analysis was used to demonstrate the relation between food groups and the blood pressure.

\section{Results}

The prevalence of hypertension in the whole studied population was $22.6 \%$ and the above prevalence regards to the sex of the participants was $21.1 \%$ for men and $24 \%$ for women while was not significant $(\mathrm{P}=0.809)$. Table 1 shows the prevalence of hypertension in different age groups. The prevalence of obesity in patients with hypertension was $30.3 \%$ which regards to the sex of the participants it was $63.9 \%$ for men and $79.0 \%$ for women. The prevalence of obesity in different age groups of $15-24,25-34,35-44,45-54,55-64$ and $65-74$ years were $27.3 \%, 73.1 \%$, $78.3 \%, 84.1 \%, 74.5 \%$ and $66.1 \%$ respectively.

\begin{tabular}{|c|c|c|c|c|}
\hline S. No. & Age groups & \multicolumn{2}{|c|}{ Blood pressure } & P value \\
\hline & & Don't have & Have & \\
\hline 1. & $15-24$ & 801 & 11 & $<0.0001$ \\
\hline & Percent & $98.6 \%$ & $1.4 \%$ & \\
\hline 2. & $25-34$ & 1043 & 26 & \\
\hline 3. & Percent & $97.6 \%$ & $2.4 \%$ & \\
\hline & $35-44$ & 957 & 93 & \\
\hline 4. & Percent & $91.1 \%$ & $8.9 \%$ & \\
\hline & $45-54$ & 907 & 296 & \\
\hline 5. & Percent & $75.4 \%$ & $24.6 \%$ & \\
\hline & $55-64$ & 537 & 483 & \\
\hline 6. & Percent & $52.6 \%$ & $47.4 \%$ & \\
\hline & $65-74$ & 229 & 315 & \\
\hline & Percent & $42.1 \%$ & $57.9 \%$ & \\
\hline
\end{tabular}

Table 1: The prevalence of hypertension in different age groups.
Table 2 shows the prevalence of overweight and obesity in patients with high blood pressure on order to their gender and different group ages. The results show that among all group ages those who never consumed low-fat and high-fat dairy, red meat, whole grains, white grains, solid oils, butter and cream and sweets, had the highest frequency of usage among participants. Daily use for salt and fruits and weekly use for vegetables, nuts, drinks and fried foods were reported as groups with the highest frequency of usage among participants.

Table 3 shows the frequency of food groups' consumption in both genders in different ages. The predictive food factors of blood pressure have been also reviewed in the conducted evaluations in this research. After adjusting for potential confounding variables, the chance of having hypertension for those who had a weekly consumption of white grain was $0.3(p<0.05)$ more than those who consumed it on a monthly basis. That is, the average weekly consumption of white grains increases the risk of developing blood pressure relative to the monthly consumption of this food group. In our study, the monthly consumption of legumes relative to weekly consumption or non-consumption of this group of foods reduces the risk of high blood pressure by 0.6 times.

\section{Discussion}

In this study, the prevalence of obesity in hypertension population was $30.3 \%$. There are various studies about the relationship between obesity and increased blood pressure. The results of some studies have showed a significant relationship between obesity and hypertension. These studies have important implications on community health, since hypertension in childhood can be associated with an increased risk of cardiovascular disease at older ages in Mexico that was conducted on Mexican 8-10 years old children who had low socioeconomic status showed the prevalence of high blood pressure $[11,12]$. The results of a research by Gopinath et al. showed a strong relationship between fat tissue and BP during childhood [13].

In Iran, the obtained results from Mazloom's study on high blood pressure patients showed the high prevalence of obesity in them [14]. In our study, a significant relationship was found between obesity and blood pressure. The prevalence of obesity in women with high blood pressure was more than men and in the age group of 45-54 years was more than the other age groups. One of the most important effective factors on the increased blood pressure is food and nutrition pattern of people. The obtained data from statistical analysis in our study showed that unhealthy food pattern including no daily consumption of vegetables (raw and cooked), nuts, low fat diary, white grains and weekly consumption of fried foods has been reported in majority of this population. Vegetables and fruits are one of the most sources of vitamins, minerals and fiber. Recommendation of food pyramid for daily consumption of vegetable is 3-5 units and for fruits is 2-3 units. Various studies have been conducted about the importance of

\begin{tabular}{|c|c|c|}
\hline Genders and age groups & Percentage & P value \\
\hline Men & $9.3 \%$ & $<0.0001$ \\
\hline Women & $16.9 \%$ & \\
\hline $15-24$ & $5.6 \%$ & $<0.0001$ \\
\hline $25-34$ & $11.5 \%$ & \\
\hline $35-44$ & $18.7 \%$ & \\
\hline $45-54$ & $24 \%$ & \\
\hline $55-64$ & $23 \%$ & \\
\hline $65-74$ & $17.6 \%$ & \\
\hline
\end{tabular}

Table 2: The prevalence of obesity based on body mass index in both genders and age groups. 
Citation: Khatibi M, Bagherzadeh S, Aghamolaey H, Najafipour H (2018) Prevalence and Risk Factors of Hypertension in the Urban Population of Iran. J Hypertens (Los Angel) 7: 253. doi: 10.4172/2167-1095.1000253

Page 3 of 6

\begin{tabular}{|c|c|c|c|c|c|c|}
\hline Food groups & $\begin{array}{c}\text { Genders and age } \\
\text { groups }\end{array}$ & Never & Monthly & Weekly & Daily & $P$ value \\
\hline \multirow{8}{*}{ Fruits } & Men & $2.2 \%$ & $1.1 \%$ & $33.2 \%$ & $63.5 \%$ & $<0.0001$ \\
\hline & Women & $4.2 \%$ & $2.1 \%$ & $35.5 \%$ & $58.2 \%$ & \\
\hline & $15-24$ & & & $40.0 \%$ & $60.0 \%$ & $<0.0001$ \\
\hline & $25-34$ & $3.8 \%$ & $3.8 \%$ & $42.3 \%$ & $50.0 \%$ & \\
\hline & $35-44$ & $2.2 \%$ & $2.2 \%$ & $35.5 \%$ & $60.2 \%$ & \\
\hline & $45-54$ & $4.5 \%$ & $1.7 \%$ & $31.7 \%$ & $62.1 \%$ & \\
\hline & $55-64$ & $3.1 \%$ & $1.3 \%$ & $33.3 \%$ & $62.3 \%$ & \\
\hline & $65-74$ & $2.6 \%$ & $2.3 \%$ & $34.0 \%$ & $61.2 \%$ & \\
\hline \multirow{8}{*}{ Vegetable } & Men & $17.4 \%$ & $6.1 \%$ & $64.0 \%$ & $12.4 \%$ & $<0.0001$ \\
\hline & Women & $21.4 \%$ & $7.6 \%$ & $56.3 \%$ & $14.6 \%$ & \\
\hline & $15-24$ & $20.0 \%$ & $10.0 \%$ & $50.0 \%$ & $20.0 \%$ & $<0.0001$ \\
\hline & $25-34$ & $11.5 \%$ & $11.5 \%$ & $73.1 \%$ & $3.8 \%$ & \\
\hline & $35-44$ & $10.8 \%$ & $5.4 \%$ & $72.0 \%$ & $11.8 \%$ & \\
\hline & $45-54$ & $14.5 \%$ & $6.1 \%$ & $64.2 \%$ & $15.2 \%$ & \\
\hline & $55-64$ & $20.6 \%$ & $6.4 \%$ & $57.2 \%$ & $15.8 \%$ & \\
\hline & $65-74$ & $21.9 \%$ & $7.3 \%$ & $59.7 \%$ & $11.1 \%$ & \\
\hline \multirow{8}{*}{ High fat dairy } & Men & $98.4 \%$ & $0 \%$ & $50 \%$ & $0.5 \%$ & $<0.0001$ \\
\hline & Women & $98.3 \%$ & $0.1 \%$ & $1.2 \%$ & $0.4 \%$ & \\
\hline & $15-24$ & $81.8 \%$ & & & $18.2 \%$ & $<0.0001$ \\
\hline & $25-34$ & $100.0 \%$ & & $1.1 \%$ & & \\
\hline & $35-44$ & $98.9 \%$ & & $3.1 \%$ & & \\
\hline & $45-54$ & $96.2 \%$ & & $0.6 \%$ & & \\
\hline & $55-64$ & $99.4 \%$ & & $0.3 \%$ & & \\
\hline & $65-74$ & $99.0 \%$ & & & & \\
\hline \multirow{8}{*}{ Low fat dairy } & Men & $96.5 \%$ & & $0.6 \%$ & $2.9 \%$ & $<0.0001$ \\
\hline & Women & $95.5 \%$ & & $0.6 \%$ & $3.9 \%$ & \\
\hline & $15-24$ & $100.0 \%$ & & & & $<0.0001$ \\
\hline & $25-34$ & $96.0 \%$ & & & & \\
\hline & $35-44$ & $98.8 \%$ & & & $1.2 \%$ & \\
\hline & $45-54$ & $96.8 \%$ & & $0.8 \%$ & $2.4 \%$ & \\
\hline & $55-64$ & $94.4 \%$ & & $1.0 \%$ & $4.6 \%$ & \\
\hline & $65-74$ & $95.3 \%$ & & $0.4 \%$ & $4.4 \%$ & \\
\hline \multirow{8}{*}{ Whole grain } & Men & $96.7 \%$ & $0.0 \%$ & $0.0 \%$ & $3.3 \%$ & $<0.0001$ \\
\hline & Women & $95.8 \%$ & $0.2 \%$ & $0.2 \%$ & $3.9 \%$ & \\
\hline & $15-24$ & $100.0 \%$ & & & & $<0.0001$ \\
\hline & $25-34$ & $100.0 \%$ & & & $4.8 \%$ & \\
\hline & $35-44$ & $95.2 \%$ & & & $3.2 \%$ & \\
\hline & $45-54$ & $96.8 \%$ & & & $5.3 \%$ & \\
\hline & $55-64$ & $94.4 \%$ & $0.2 \%$ & $0.4 \%$ & $2.6 \%$ & \\
\hline & $65-74$ & $97.1 \%$ & $1.0 \%$ & $0.6 \%$ & $1.3 \%$ & \\
\hline \multirow{8}{*}{ White grain } & Men & $97.1 \%$ & $2.3 \%$ & $0.9 \%$ & $1.1 \%$ & $<0.0001$ \\
\hline & Women & $95.7 \%$ & - & - & & \\
\hline & $15-24$ & $100.0 \%$ & & & & $<0.0001$ \\
\hline & $25-34$ & $95.8 \%$ & & $4.2 \%$ & & \\
\hline & $35-44$ & $91.5 \%$ & $2.4 \%$ & $6.1 \%$ & & \\
\hline & $45-54$ & $96.3 \%$ & $1.6 \%$ & $0.4 \$$ & $1.6 \%$ & \\
\hline & $55-64$ & $96.5 \%$ & $2.5 \%$ & $0.3 \%$ & $0.8 \%$ & \\
\hline & $65-74$ & $97.0 \%$ & $1.5 \%$ & $0.4 \%$ & $1.1 \%$ & \\
\hline \multirow{8}{*}{ Fried foods } & Men & $14.2 \%$ & $5.9 \%$ & $59.5 \%$ & $20.4 \%$ & $<0.0001$ \\
\hline & Women & $20.6 \%$ & $8.9 \%$ & $57.3 \%$ & $13.2 \%$ & \\
\hline & $15-24$ & & & $81.8 \%$ & $18.2 \%$ & $<0.0001$ \\
\hline & $25-34$ & $11.5 \%$ & & $46.2 \%$ & $42.3 \%$ & \\
\hline & $35-44$ & $9.7 \%$ & $5.4 \%$ & $54.8 \%$ & $30.1 \%$ & \\
\hline & $45-54$ & $13.5 \%$ & $7.1 \%$ & $58.4 \%$ & $20.9 \%$ & \\
\hline & $55-64$ & $19.5 \%$ & $7.7 \%$ & $56.3 \%$ & $16.4 \%$ & \\
\hline & $65-74$ & $21.3 \%$ & $9.6 \%$ & $61.8 \%$ & $7.3 \%$ & \\
\hline
\end{tabular}


Citation: Khatibi M, Bagherzadeh S, Aghamolaey H, Najafipour H (2018) Prevalence and Risk Factors of Hypertension in the Urban Population of Iran. J Hypertens (Los Angel) 7: 253. doi: 10.4172/2167-1095.1000253

Page 4 of 6

\begin{tabular}{|c|c|c|c|c|c|c|}
\hline \multirow{9}{*}{ Butter and cream } & Men & $89.2 \%$ & $0.0 \%$ & $10.1 \%$ & $0.7 \%$ & $<0.0001$ \\
\hline & Women & $94.4 \%$ & $0.1 \%$ & $4.9 \%$ & $0.5 \%$ & \\
\hline & $15-24$ & $90.0 \%$ & & $10.0 \%$ & & $<0.0001$ \\
\hline & $25-34$ & $88.5 \%$ & & $11.5 \%$ & & \\
\hline & $35-44$ & $82.8 \%$ & & $16.1 \%$ & & \\
\hline & $45-54$ & $86.8 \%$ & & $11.9 \%$ & & \\
\hline & $55-64$ & $94.8 \%$ & & $4.6 \%$ & & \\
\hline & $65-74$ & $94.6 \%$ & & $5.1 \%$ & & \\
\hline & & $91.7 \%$ & & $7.5 \%$ & & \\
\hline \multirow{8}{*}{ Fats } & Men & $70.3 \%$ & $1.2 \%$ & $15.9 \%$ & $12.6 \%$ & $<0.0001$ \\
\hline & Women & $63.3 \%$ & $0.7 \%$ & $15.6 \%$ & $20.4 \%$ & \\
\hline & $15-24$ & $50.0 \%$ & & $25.0 \%$ & $25.0 \%$ & $<0.0001$ \\
\hline & $25-34$ & $79.2 \%$ & & $4.2 \%$ & $16.7 \%$ & \\
\hline & $35-44$ & $61.7 \%$ & $2.5 \%$ & $16.0 \%$ & $19.8 \%$ & \\
\hline & $45-54$ & $54.5 \%$ & $1.2 \%$ & $20.8 \%$ & $23.5 \%$ & \\
\hline & $55-64$ & $71.0 \%$ & $1.0 \%$ & $14.9 \%$ & $13.2 \%$ & \\
\hline & $65-74$ & $70.7 \%$ & $0.4 \%$ & $13.8 \%$ & $15.2 \%$ & \\
\hline \multirow{8}{*}{ Salt } & Men & $32.6 \%$ & $2.0 \%$ & $5.6 \%$ & $59.8 \%$ & $<0.0001$ \\
\hline & Women & $33.4 \%$ & $0.5 \%$ & $4.8 \%$ & $61.2 \%$ & \\
\hline & $15-24$ & $18.2 \%$ & & $18.2 \%$ & $63.6 \%$ & $<0.0001$ \\
\hline & $25-34$ & $19.2 \%$ & & $3.8 \%$ & $76.9 \%$ & \\
\hline & $35-44$ & $26.1 \%$ & $1.1 \%$ & $6.5 \%$ & $66.3 \%$ & \\
\hline & $45-54$ & $31.6 \%$ & $1.0 \%$ & $5.4 \%$ & $61.9 \%$ & \\
\hline & $55-64$ & $31.7 \%$ & $1.0 \%$ & $5.0 \%$ & $62.3 \%$ & \\
\hline & $65-74$ & $38.3 \%$ & $1.3 \%$ & $5.1 \%$ & $55.3 \%$ & \\
\hline \multirow{9}{*}{ Drinks } & Men & $55.5 \%$ & $15.4 \%$ & $27.1 \%$ & $2.0 \%$ & $<0.0001$ \\
\hline & Women & $64.6 \%$ & $15.0 \%$ & $18.4 \%$ & $1.9 \%$ & \\
\hline & $15-24$ & $30.0 \%$ & $30.0 \%$ & $40.0 \%$ & & $<0.0001$ \\
\hline & $25-34$ & $30.8 \%$ & $15.4 \%$ & $46.2 \%$ & $7.7 \%$ & \\
\hline & $35-44$ & $45.2 \%$ & $15.1 \%$ & $35.5 \%$ & $4.3 \%$ & \\
\hline & $45-54$ & $55.6 \%$ & $15.6 \%$ & $26.4 \%$ & $2.4 \%$ & \\
\hline & $55-64$ & $66.4 \%$ & & $18.7 \%$ & $1.5 \%$ & \\
\hline & $65-74$ & $65.3 \%$ & $13.5 \%$ & $17.8 \%$ & $1.3 \%$ & \\
\hline & & & $15.6 \%$ & & & \\
\hline \multirow{8}{*}{ Nuts } & Men & $27.4 \%$ & $24.3 \%$ & $40.8 \%$ & $7.4 \%$ & $<0.0001$ \\
\hline & Women & $34.4 \%$ & $22.8 \%$ & $35.2 \%$ & $7.6 \%$ & \\
\hline & $15-24$ & & $50.0 \%$ & $33.3 \%$ & $16.7 \%$ & $<0.0001$ \\
\hline & $25-34$ & $16.0 \%$ & $20.0 \%$ & $52.0 \%$ & $12.0 \%$ & \\
\hline & $35-44$ & $25.3 \%$ & $21.7 \%$ & $43.4 \%$ & $9.6 \%$ & \\
\hline & $45-54$ & $26.2 \%$ & $23.8 \%$ & $45.2 \%$ & $4.8 \%$ & \\
\hline & $55-64$ & $30.1 \%$ & $24.0 \%$ & $37.2 \%$ & $8.8 \%$ & \\
\hline & $65-74$ & $37.1 \%$ & $23.2 \%$ & $32.4 \%$ & $7.4 \%$ & \\
\hline \multirow{8}{*}{ Sweets } & Men & $73.1 \%$ & $0.0 \%$ & $5.4 \%$ & $21.5 \%$ & $<0.0001$ \\
\hline & Women & $84.9 \%$ & $0.1 \%$ & $3.8 \%$ & $11.2 \%$ & \\
\hline & $15-24$ & $54.5 \%$ & & $36.4 \%$ & $9.1 \%$ & $<0.0001$ \\
\hline & $25-34$ & $80.8 \%$ & & $3.8 \%$ & $15.4 \%$ & \\
\hline & $35-44$ & $76.3 \%$ & & $4.3 \%$ & $18.3 \%$ & \\
\hline & $45-54$ & $76.2 \%$ & & $6.1 \%$ & $17.7 \%$ & \\
\hline & $55-64$ & $82.3 \%$ & & $3.5 \%$ & $14.1 \%$ & \\
\hline & $65-74$ & $81.5 \%$ & & $3.8 \%$ & $14.6 \%$ & \\
\hline \multirow{8}{*}{ Meats } & Men & $468(95.5 \%)$ & $1(0.2 \%)$ & $19(3.9 \%)$ & $2(0.4 \%)$ & $<0.0001$ \\
\hline & Women & $95.2 \%$ & $0.5 \%$ & $3.8 \%$ & $0.6 \%$ & \\
\hline & $15-24$ & $100.0 \%$ & & & & $<0.0001$ \\
\hline & $25-34$ & $96.0 \%$ & & $4.0 \%$ & & \\
\hline & $35-44$ & $96.4 \%$ & & $3.6 \%$ & & \\
\hline & $45-54$ & $95.2 \%$ & $0.8 \%$ & $2.8 \%$ & $1.2 \%$ & \\
\hline & $55-64$ & $95.1 \%$ & $0.2 \%$ & $4.4 \%$ & $0.2 \%$ & \\
\hline & $65-74$ & $93.8 \%$ & $0.4 \%$ & $5.4 \%$ & $0.4 \%$ & \\
\hline
\end{tabular}




\begin{tabular}{|c|c|c|c|c|c|c|}
\hline \multirow{8}{*}{ Rice and spaghetti } & Men & $46.0 \%$ & - & $32.3 \%$ & $21.7 \%$ & $<0.0001$ \\
\hline & Women & $46.7 \%$ & - & $31.4 \%$ & $21.9 \%$ & \\
\hline & $15-24$ & $16.7 \%$ & - & $66.7 \%$ & $16.7 \%$ & $<0.0001$ \\
\hline & $25-34$ & $12.0 \%$ & - & $48.0 \%$ & $40.0 \%$ & \\
\hline & $35-44$ & $22.9 \%$ & - & $37.3 \%$ & $39.8 \%$ & \\
\hline & $45-54$ & $37.3 \%$ & - & $35.3 \%$ & $27.3 \%$ & \\
\hline & $55-64$ & $49.8 \%$ & & $29.9 \%$ & $20.4 \%$ & \\
\hline & $65-74$ & $57.1 \%$ & & $28.0 \%$ & $14.9 \%$ & \\
\hline \multirow{8}{*}{ Legumes } & Men & $25.4 \%$ & $6.1 \%$ & $68.2 \%$ & $0.2 \%$ & $<0.0001$ \\
\hline & Women & $34.4 \%$ & $8.9 \%$ & $56.0 \%$ & $0.6 \%$ & \\
\hline & $15-24$ & $33.3 \%$ & & $66.7 \%$ & & $<0.0001$ \\
\hline & $25-34$ & $20.0 \%$ & & $80.0 \%$ & & \\
\hline & $35-44$ & $18.1 \%$ & $6.0 \%$ & $74.7 \%$ & $1.2 \%$ & \\
\hline & $45-54$ & $30.9 \%$ & $7.2 \%$ & $61.0 \%$ & $0.8 \%$ & \\
\hline & $55-64$ & $30.1 \%$ & $7.5 \%$ & $61.9 \%$ & $0.5 \%$ & \\
\hline & $65-74$ & $30.3 \%$ & $9.9 \%$ & $59.9 \%$ & & \\
\hline \multirow{8}{*}{ Fast foods } & Men & $73.0 \%$ & $16.8 \%$ & $9.7 \%$ & $0.5 \%$ & $<0.0001$ \\
\hline & Women & $76.3 \%$ & $15.5 \%$ & $8.1 \%$ & $0.1 \%$ & \\
\hline & $15-24$ & $9.1 \%$ & $63.6 \%$ & $18.2 \%$ & $9.1 \%$ & $<0.0001$ \\
\hline & $25-34$ & $42.3 \%$ & $19.2 \%$ & $38.5 \%$ & & \\
\hline & $35-44$ & $51.6 \%$ & $24.7 \%$ & $22.6 \%$ & $1.1 \%$ & \\
\hline & $45-54$ & $69.6 \%$ & $20.5 \%$ & $9.6 \%$ & $0.3 \%$ & \\
\hline & $55-64$ & $76.5 \%$ & $16.0 \%$ & $7.3 \%$ & $0.2 \%$ & \\
\hline & $65-74$ & $84.0 \%$ & $10.6 \%$ & $5.4 \%$ & & \\
\hline
\end{tabular}

Table 3: The frequency of food groups' consumption in both genders in different ages.

vegetables consumption as a fiber source in controlling and preventing of blood pressure [14-16].

A study in Iran by Rohani et al. showed that diet with low glycemic index (vegetables have low glycemic index) has no effect on obesity and blood pressure [17]. In our study, daily consumption of fried foods increased the probability of high blood pressure incidence, 0.4 times more than monthly consumption of these foods. Our study confirmed of the result of S. Eilat-Adar study [14].

In a study, Iran has been reported as the first rank in using solid vegetable oil in the Middle East. This study states that the annual consumption of beverages in Iran is 42 liters, while in the world is 1210 liters $[17,18]$.

Another study Van Maijl et al. found that, daily intake of lowfat dairy products reduced the systolic blood pressure for 8 weeks in obese subjects, but did not improve other risk factors that caused the metabolic syndrome [19]. In the evaluations conducted in our survey, the nutritional factors predictive of blood pressure have also been studied. According to our study, the weekly consumption of white cereals increased by 0.3 times the monthly intake of blood pressure. A study in 2008-2010, high intake of fiber and vitamins can have protective effects against hypertension [15].

Legumes are sources of fiber richness and, on the other hand, they are considered as the source of plant proteins. There are some studies that showed increasing of fiber intake from whole grains and legumes is associated with a reduction in the incidence of hypertension $[15,19]$. In our study, the monthly consumption of legumes compared with weekly intake or non-consumption of this group of foods reduces the risk of high blood pressure by 0.6 times. The result of our plan was inconsistent with the result of some surveys. Nuts (pistachio, almond, walnut and etc.) are considered as rich sources of essential fatty acids, PuFA and fiber in diet. This food group has especial value in all ages' diet. The recommendation of food pyramid is daily consumption of this food group.
A study by Mirmiran showed that low intake of fruits and nuts increased hypertension incidence [20]. In our study, the majority of the hypertension participants reported weekly consumption of the nuts, that it increased the risk of developing blood pressure by 0.7 times more than monthly consumption. This is likely due to the fact that in our country the consumption of the nuts is soaked in salt. It probably the added salt to the nuts has increased the likelihood of elevated blood pressure. Modifying unhealthy dietary habits include low or nonconsuming fatty and salty foods, high fruits and vegetables intakes, eating healthy snacks, low or non- consuming of sweets, making suitable use of fish can be a preventative factor for cardiovascular disease [20]. In our study, the majority of people reported weekly consumption of fried foods and daily intake of salt, while consumption of sweets, fast food, fats, and high-fat dairy products was not reported by the majority of the population. Also in our study, the results showed that daily sweets intake in comparison with monthly intake increased hypertension incidence by 2.2 times $(\mathrm{p}<0.05)$. Payab et al. showed that consuming sweets and sweet drinks is related significantly to anthropometry and blood pressure of the participants in some studies [21]. In our study, daily consumption of drinks can increase the chance of high blood pressure by 0.6 times more than monthly intake $(\mathrm{P}<0.05)$. Furthermore, based on our study, weekly consumption of fast foods increased the risk of high blood pressure incidence by 0.7 times more than monthly consumption. A study by S. Eilat-Adar and colleagues showed that unhealthy dietary patterns involved, high consuming of high energy foods, saturated fatty acids, animal fats, high intake of sweets and sweets drinks reduced the fruits and vegetables intake. Increased consumption of fast foods had a direct relationship with CVD risk factors [14]. Thus, it appears that the results obtained from our plan, except in few cases, are consistent with many of the results of other initiatives in our country and in other countries, that these emphasize the observance of a healthy diet to prevent or control high blood pressure. 
Citation: Khatibi M, Bagherzadeh S, Aghamolaey H, Najafipour H (2018) Prevalence and Risk Factors of Hypertension in the Urban Population of Iran. J Hypertens (Los Angel) 7: 253. doi: 10.4172/2167-1095.1000253

\section{Conclusion}

Obesity is related directly to other cardiovascular diseases and mortality due to them. Based on the results of this study, the necessity of modifying nutritional cultures, nutritional education for these patients, weight control method and informing them of the impact of their diet on improving their illnesses are effective, while reducing the over-thecounter costs of clinical treatments for patients and the community.

\section{References}

1. Musaiger AO, Al-Hazzaa HM (2012) Prevalence and risk factors associated with nutrition-related noncommunicable diseases in the Eastern Mediterranean region. Int J Gen Med 5: 199-217.

2. Motlagh B, O'donnell M, Yusuf S (2009) Prevalence of cardiovascular risk factors in the Middle East: a systematic review. Eur J Cardiovasc Prev Rehabil 16: $268-280$.

3. Martins MdCdC, Ricarte IF, Rocha CHL, Maia RB, Silva VBd, et al. (2010) Blood pressure, excess weight and level of physical activity in students of a public university. Arq Bras Cardiol 95: 192-199.

4. Azizi F, Ghanbarian A, Madjid M, Rahmani M (2002) Distribution of blood pressure and prevalence of hypertension in Tehran adult population: Tehran Lipid and Glucose Study (TLGS), 1999-2000. J Hum Hypertens 16: 305-312.

5. Chobanian AV, Bakris GL, Black HR, Cushman WC, Green LA, et al. (2003) Seventh report of the joint national committee on prevention, detection, evaluation, and treatment of high blood pressure. Hypertension 42: 1206-1252.

6. Sabuncu T, Arikan E, Tasan E, Hatemi H (1999) Comparison of the associations of body mass index, percentage body fat, waist circumference and waist/hip ratio with hypertension and other cardiovascular risk factors. Turkish Journal of Endocrinology and Metabolism 3: 137-142.

7. Harris MM, Stevens J, Thomas N, Schreiner P, Folsom AR (2000) Associations of fat distribution and obesity with hypertension in a bi-ethnic population: the ARIC study. Obes Res 8: 516-524.

8. Sironi AM, Gastaldelli A, Mari A, Ciociaro D, Postano V, et al. (2004) Viscera fat in hypertension: influence on insulin resistance and $\beta$-cell function. Hypertension. 44: 127-133

9. Siani A, Cappuccio FP, Barba G, Trevisan M, Farinaro E, et al. (2002) The relationship of waist circumference to blood pressure: the Olivetti Heart Study. Am J Hypertens 15: 780-786.
10. Tribble DL (1999) Antioxidant consumption and risk of coronary heart disease: emphasis on vitamin $C$, vitamin $E$, and $\beta$-carotene: a statement for healthcare professionals from the American Heart Association. Circulation 99: 591-955.

11. Morrison G, Hark L (1996) Medical nutrition and disease. In: Blackwell Science.

12. Colín-Ramírez E, Castillo-Martínez L, Orea-Tejeda A, Romero ARV, Castañeda $\mathrm{AV}$, et al. (2009) Waist circumference and fat intake are associated with high blood pressure in Mexican children aged 8 to 10 years. J Am Diet Assoc 109 996-1003.

13. Gopinath B, Baur LA, Garnett S, Pfund N, Burlutsky G, et al. (2011) Body mass index and waist circumference are associated with blood pressure in preschoolaged children. Annals of Epidemiology. 21: 351-357.

14. Mazloum Z, Hejazi N, Ekramzadeh M (2010) Anthropometric Measurements and its Relation to Hypertension in Cardiovascular Diseased Patients. Pars Journal of Medical Sciences 7: 16-22.

15. Eilat-Adar S, Mete M, Fretts A, Fabsitz R, Handeland V, et al. (2013) Dietary patterns and their association with cardiovascular risk factors in a population undergoing lifestyle changes: The Strong Heart Study. Nutr Metab Cardiovas Dis 23: $528-535$.

16. Hosseinpour-Niazi S, Mirmiran P, Fallah-Ghohroudi A, Azizi F (2015) Combined effect of unsaturated fatty acids and saturated fatty acids on the metabolic syndrome: Tehran lipid and glucose study. J Health Popul Nutr 33: 5.

17. Rouhani MH, Kelishadi R, Hashemipour M, Esmaillzadeh A, Azadbakht L (2013) The effect of low glycemic index diet on body weight status and blood pressure in overweight adolescent girls: a randomized clinical trial. Nutr Res Pract 7: 385-392.

18. Imani Pour M (2009) Knowledge and Attitude of educators about cardiovascular disease. Iran J Nurs 22: 40-32.

19. van Meijl LE, Mensink RP (2011) Low-fat dairy consumption reduces systolic blood pressure, but does not improve other metabolic risk parameters in overweight and obese subjects. Nutr Metab Cardiovasc Dis 21: 355-361.

20. Mirmiran P, Noori N, Zavareh MB, Azizi F (2009) Fruit and vegetable consumption and risk factors for cardiovascular disease. Metabolism 58: 460-468.

21. Payab M, Kelishadi R, Qorbani M, Motlagh ME, Ranjbar SH, et al. (2015) Association of junk food consumption with high blood pressure and obesity in Iranian children and adolescents: The CASPIAN-IV Study. J Pediatr 91: 196-205. 